\title{
The significance and impact of the Polish Anti-tobacco Law
}

\author{
Mateusz Zatoński ${ }^{1,2}$, Witold A. Zatoński ${ }^{2,3}$, Krzysztof Przewoźniak ${ }^{2,3}$, Marek Jaworskiं ${ }^{2,3}$ \\ 'London School of Hygiene and Tropical Medicine, London, UK \\ ${ }^{2}$ Health Promotion Foundation, Nadarzyn, Poland \\ ${ }^{3}$ Maria Skłodowska-Curie Memorial Cancer Center and Institute of Oncology, Warsaw, Poland
}

\begin{abstract}
By the end of the 1980s Poland was at the brink of a health catastrophe. Cardiovascular diseases and lung cancer mortality steadily increased and were among the highest ever observed in the world. Life expectancy for young adult and middle aged men reached levels similar to China and India. The main cause of this health decline was tobacco smoking. In the 1980s Poland became the country with the highest cigarette consumption in the world and smoking prevalence in both sexes was the highest in Europe. The milestone for tobacco control and health improvement was the Tobacco Control Bill passed by the Polish Sejm on 9 November 1995. The Law enforced a multitude of novel legal measures such as large health warnings on cigarette packs and a complete ban on tobacco advertising, promotion and sponsorship. The legislation was lauded by the WHO as an "example to the rest of the world". It also contributed to implementing governmental and social solutions that changed the health behaviours of Poles and had a direct effect on health outcomes. Cigarette sales dropped from 104 billion cigarettes in 1990 to 42 billion today. The prevalence of daily smoking declined from $62 \%$ in 1982 to $28 \%$ in 2014 in men and from $30 \%$ to $19 \%$ in women. Today, incidence rates for cardiovascular diseases and lung cancer in middle age men are twice lower than in the beginning of 1990s. These changes were also crucial for the substantial improvement of life expectancy in Poland, which increased at one of the fastest rates in the world in the 1990s. Now there is urgent need to formulate a plan for the eradication of smoking in Poland in the next decade and to start striving towards the tobacco endgame.
\end{abstract}

KEY WORDS: Anti-tobacco Law, Poland, legislation, smoking prevalence, tobacco-related diseases.

ADDRESS FOR CORRESPONDENCE: Mateusz Zatoński, London School of Hygiene and Tropical Medicine, Keppel Street, London WC1E 7HT, UK, phone: +44 7415240 171, e-mail: mateusz.zatonski@lshtm.ac.uk

The Law for the Protection of Health from the Consequences of using Tobacco and Tobacco Products (hereafter "Anti-tobacco Law"), was passed by the Polish Sejm (lower chamber of the Polish Parliament) on 9 November 1995, and enacted in May 1996.

The bill came as a response to the deep health crisis which engulfed Polish society by the early 1990s, and to which smoking has been a particularly significant contributor. In the 1980s Poland became the country with the highest cigarette consumption in the world, a statistical Polish adult smoked almost 3600 cigarettes per year [1], and smoking prevalence was the highest in
Europe (Fig. 1). In its report, the World Health Organisation (WHO) has shown that in 1990 a 15 -year old boy in Poland had a lower probability to live to the age of 60 than his peers in China or India [6]. Cardiovascular diseases and lung cancer mortality steadily increased and by the end of the 1980s reached in Poland one of the highest levels ever observed in the world [7]. From the early 1960s life expectancy stopped increasing, and in young and middle-aged men it began to decrease rapidly (see Health in the Polish People's Republic, pp. 7-16).

Smoking was the main preventable risk factor behind this dramatic increase in disease incidence and prema- 

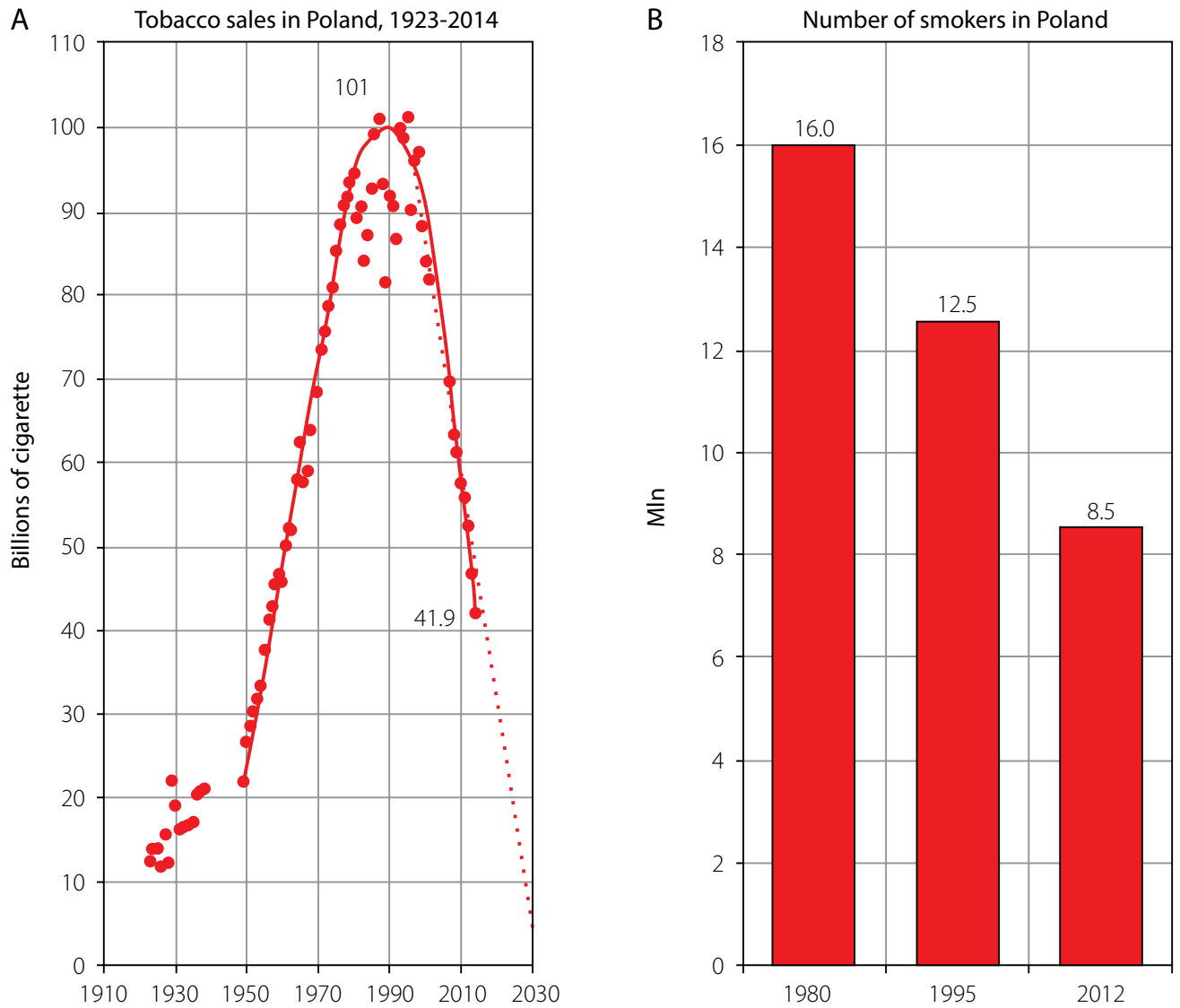

C Daily smoking by sex, 15+, Poland, 1974-2013

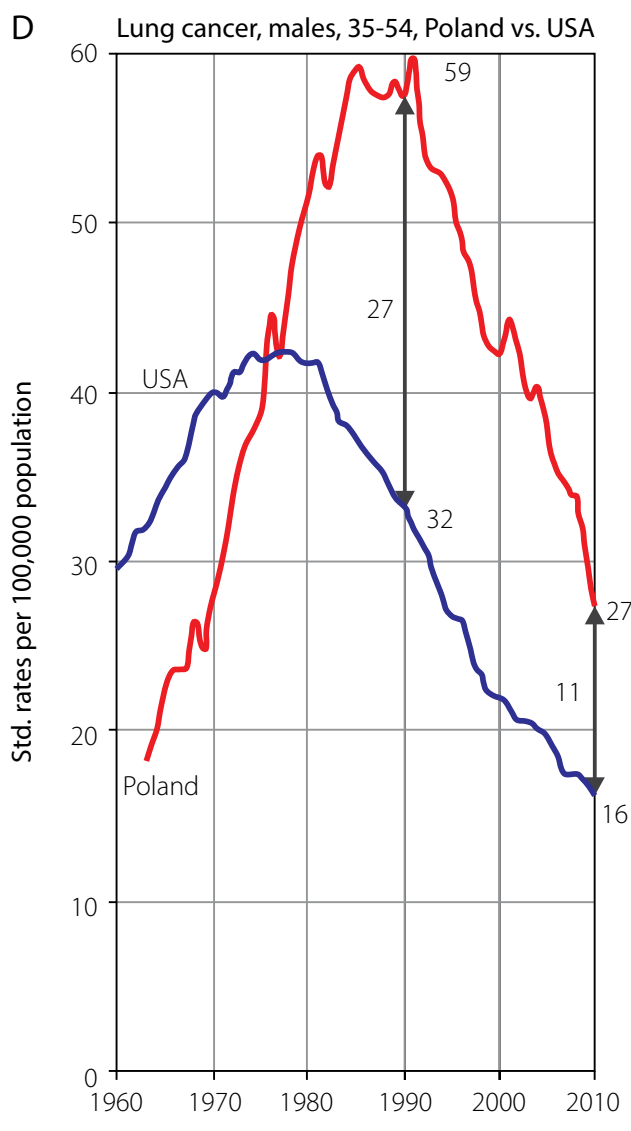

FIG. 1. Cigarette consumption and smoking in Poland vs. lung cancer [2-5] 


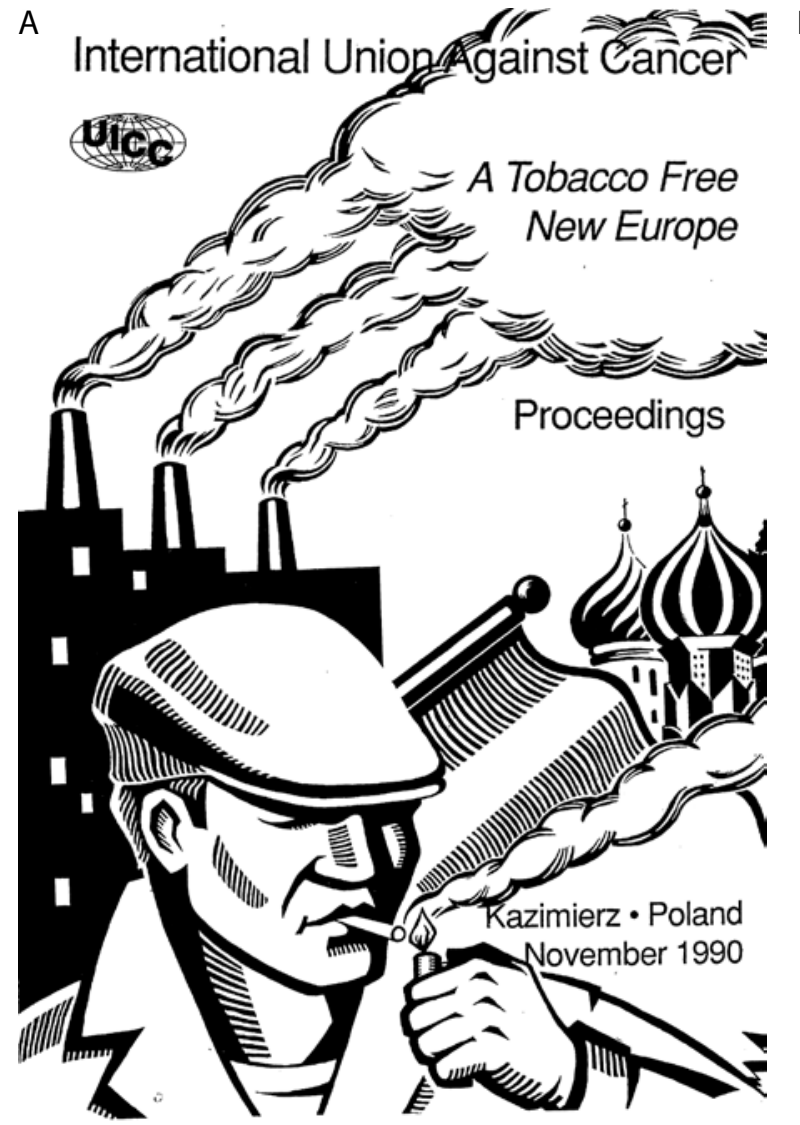

Kazimierz • Poland, $28-29$ November 1990

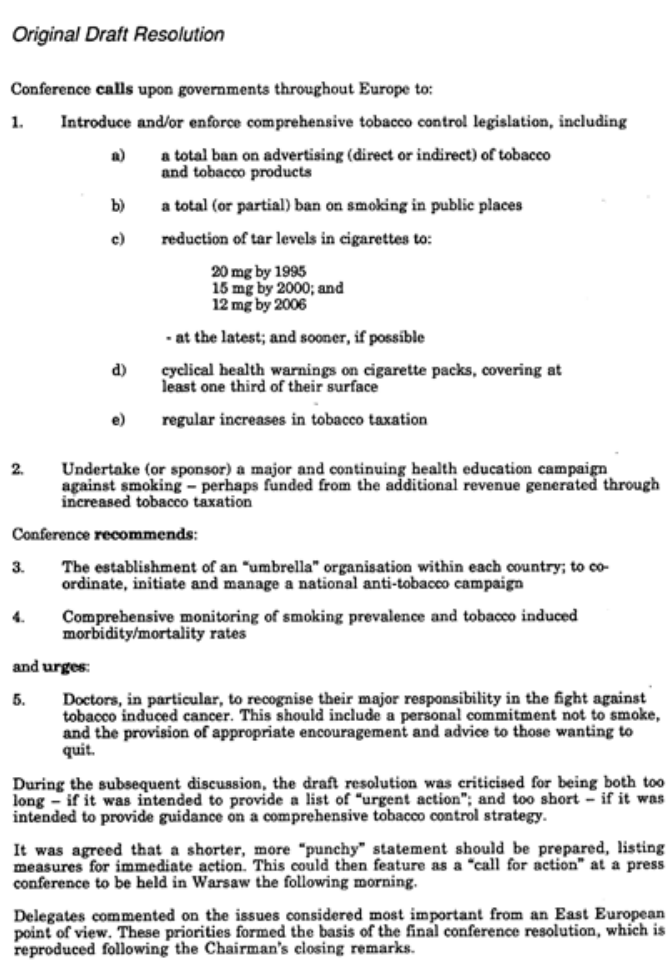

FIG. 2. Proceedings of the UICC conference "A Tobacco Free Europe" in Kazimierz, Poland with Declaration of Kazimierz

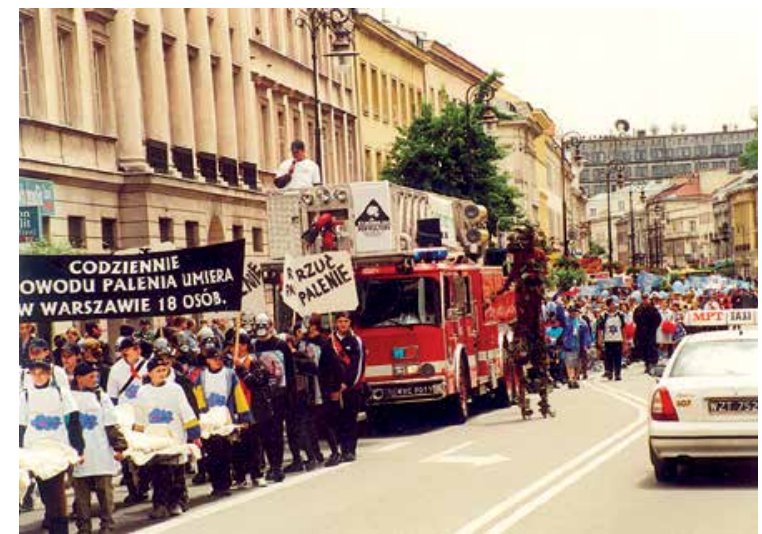

FIG. 3. A street march for smoke-free Poland organized in Warsaw as part of the Great Polish Smoke-out campaign

ture mortality. The mounting problem of tobacco-related diseases was first diagnosed in Poland in the 1980s by the growing health advocacy movement, and quickly picked up by medical associations [8]. However, after the collapse of the communist regime in 1989 there were few reasons for optimism. The Polish market quickly opened up to transnational tobacco companies, which spent $\$ 100$ million annually on advertising their products. It was estimated, that by the year 2000 the sale of cigarettes in Poland would increase by $10-20 \%$ [9].
The turning point came in November 1990, when the conference on "A Tobacco Free New Europe" was held in the Polish town of Kazimierz. It was the first international summit of world tobacco control leaders in Central and Eastern Europe (CEE), and was organised in collaboration with the International Union Against Cancer (UICC) and the American Cancer Society. During the summit, the so-called Declaration of Kazimierz was issued, calling on the governments of the democratising CEE countries to introduce legislative measures which would address the problem of smoking in the region (see Fig. 2).

From that point on pushing for a Parliamentary bill aimed at decreasing tobacco-related diseases became a priority for the anti-tobacco movement in Poland. This movement was centred around the newly formed Health Promotion Foundation (HPF), which, in the early 1990s, launched the largest health awareness campaign in CEE promoting a healthy, smoke-free lifestyle - the Great Polish Smoke-out ("Rzuć Palenie Razem z Nami”) (see Fig. 3). It is estimated that, as a result of the campaign which ran annually for more than 15 years, over four million Poles quit smoking [10].

The 1995 Anti-tobacco Law carried with it a multitude of novel legal and social solutions to the problem of smoking in Poland. The largest health text warnings in the world were introduced, covering $30 \%$ of cigarette 
packaging (see Fig. 4). One of the first governmental programmes in CEE aiming to reduce smoking prevalence was launched. Finally, one of the world's first laws on free treatment of tobacco addiction was also contained in the bill. In 1999 the Anti-tobacco Law was updated to include one of the world's first bans on the advertisement and promotion of tobacco products, and the ban on the sponsorship of media and political parties by tobacco companies [10].

Poland's efforts were noticed and praised by the public health community. The comprehensive Polish Anti-tobacco Law was lauded by the WHO as an "example to the rest of the world" [11]. Poland was considered a leader of legislative anti-tobacco measures in CEE, and invited to the group of states initiating work on the WHO Framework Convention on Tobacco Control [12]. In 2002 Poland hosted two important European conferences devoted to the struggle against the tobacco epidemic - the European Conference of Health Ministers, and the European Conference on Tobacco or Health [13].

What is most important, the legislative measures, combined with health awareness campaigns, had a direct effect on the health of Poles. The sale of cigarettes plummeted from 104 billion cigarettes in the early 1990s to 42 billion today (see Fig. 1). The prevalence of daily smoking among men declined from $62.2 \%$ in 1982 to $28 \%$ in 2014 and among women from $30 \%$ to $19 \%$ in the same period (see Fig. 1). Consequently, incidence rates for lung cancer, a disease affecting almost exclusively smokers, halved in men aged 35-54 years old (see Fig. 1). Cardiovascular disease incidence almost halved [7]. The positive changes in health behaviours that took place in the 1990s in Poland were also crucial in reversing the trend of life expectancy decline that had place in the country for the previous 30 years, replacing it with an increase in life expectancy in both sexes [14]. The health improvement in Poland between 1991 and 2002 was the fastest in the world [7].

Although the first phase of the struggle against tobacco-related diseases in Poland has been completed, an urgent need exists to formulate a plan for the eradication of smoking in the years 2016-2026. A social consensus exists favouring such measures, and the majority of smokers have declared their willingness to quit [8]. The medical community will have a particularly important role in this. It is necessary to create special intervention programmes involving doctors and pharmacists, and supported by modern technologies (telemedicine). Industry sales data suggests that the number of smokers decreased by half a million between 2011 and 2012 [4]. A reasonable strategic goal therefore should be to strive for a tobacco endgame by halving the number of smokers, from 8 to 4 million, in the next decade.

\section{DISCLOSURE}

Authors report no conflict of interest.
Before 1998

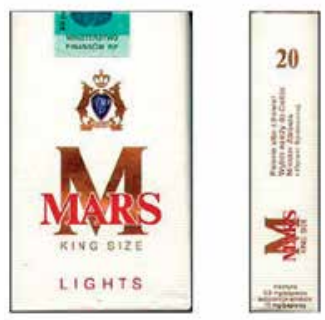

FIG. 4. Health warnings before and after the Anti-tobacco Law

\section{References}

1. World Health Organization. The Current Status of the Tobacco Epidemic in Poland. WHO Regional Office for Europe, Copenhagen 2009.

2. Zatoński W, Przewoźniak K, Sulkowska U, West R, Wojtyła A. Tobacco smoking in countries of the European Union. Ann Agric Environ Med 2012; 19: 181-192.

3. Czapiński J, Panek T (eds.). Diagnoza Społeczna 2013 [Public diagnosis 2013].

4. Dziennik Gazeta Prawna, 11 September 2014.

5. Zatoński WA, Sulkowska U, Didkowska J. Kilka uwag o epidemiologii nowotworów w Polsce [Few comment on cancer epidemiology in Poland]. Nowotwory Journal of Oncology 2015; 65: 179-196.

6. Murray CJ, Lopez AD. Global and regional cause-of-death patterns in 1990. Bulletin of the World Health Organization 1994; 72: $447-480$.

7. Zatoński $W$ and the HEM Project team. Closing the health gap in European Union. Cancer Center and Institute, Warsaw 2008.

8. Zatoński W, Zatoński M, Przewoźniak K. Health improvement in Poland is contingent on continued extensive tobacco control measures. Ann Agric Environ Med 2013; 20: 405-411.

9. Connolly GN. Worldwide expansion of transnational tobacco industry. J Natl Cancer Inst Monogr 1992; 12: 29-35.

10. Zatoński W. Droga do zdrowia. Historia przeciwdziałania epidemii chorób odtytoniowych w Polsce [The path to health. History of fighting tobacco-related diseases in Poland]. Cancer Center and Institute, Warsaw 2003.

11. Blanke DD, de Costa e Silva V. Tools for advancing tobacco control in the $21^{\text {st }}$ century. Tobacco Control Legislation: An introductory guide. World Health Organization, Geneva 2004.

12. WHO Framework Convention on Tobacco Control. World Health Organization, Geneva 2003; Polish text of the Convention available in Dz. U. nr 74/2006, poz. 487.

13. European Strategy for Tobacco Control. World Health Organization - Regional Office for Europe, Copenhagen 2002.

14. Zatoński WA, Bhala N. Changing trends of diseases in Eastern Europe: closing the gap. Public Health 2012; 126: 248-252. 